\title{
Protein Activation Pathway
}

National Cancer Institute

\section{Source}

National Cancer Institute. Protein Activation Pathway. NCI Thesaurus. Code C40420.

A sequence of biological or biochemical events that are involved in the manifestation of the activity of a protein. 